\title{
A dinâmica social do desrespeito: para a situação de uma teoria crítica da sociedade ${ }^{1-2}$
}

Axel Honneth ${ }^{3}$

\section{Resumo}

Neste artigo, que é originalmente um discurso de posse no Instituto Otto Suhr na Universidade Livre de Berlin, Axel Honneth esboça o programa de uma teoria intersubjetiva do reconhecimento, utilizando esta última categoria como o núcleo conceitual de uma Teoria Crítica da sociedade na qual a experiência pré-cientifica de desrespeito às expectativas sociais se conecta à formação de demandas emancipatórias.

Palauras-chave: Teoria Crítica; Reconhecimento; Desrespeito; Experiência pré-científica.

\section{Abstract}

In this article, which originally is the text of Axel Honneth's inaugural speech at the the OttoSuhr-Institut at the Free University of Berlin, the author delineates the program of an intersubjective theory of recognition, taking that category as the conceptual core of a Critical Theory of society in which pre-theoretical experiences of disrespect of one's social expectations are connected to the emergence of emancipatory claims.

Keywords: Critical Theory; Recognition; Disrespect; Pre-theoretical experience.

1 Trata-se do texto de minha palestra inaugural no Otto-Suhr-Institut na Freie Universität Berlin em novembro de 1993. Uma versão inicial apareceu em Leviathan I/I994.

2 Originalmente publicado como "Die soziale Dynamik von Missachtung. Zur Ortbestimmung einer Kritischen Gesellschaftstheorie", em HONNETH, Axel. Das Andere der Gerechtigkeit. Aufsätze zur praktischen Philosophie. Frankfurt am Main: Suhrkamp, 2000. p. 88-109. Traduzido do original alemão com permissão da Editora Suhrkamp por Luiz Gustavo da Cunha de Souza.

3 Axel Honneth é o Professor Jack C. Weinstein de Humanidades no Departmento de Filosofia na Columbia University; foi diretor do Instituto para Pesquisa Social (Institut für Sozialforschung) na Goethe-Universität em Frankfurt am Main entre 2001 e 2018 e Professor de Filosofia Social na mesma universidade entre 1996 e 2016.

\section{$(\infty))$ EY}

Direito autoral e licença de uso: Este artigo está licenciado sob uma Licença Creative Commons. Com essa licença você pode compartilhar, adaptar, para qualquer fim, desde que atribua a autoria da obra, forneça um link para a licença, e indicar se foram feitas alterações. 
Quem hoje empreende a tentativa de situar a "Teoria Crítica” se expóe facilmente à suspeita de um mal-entendido nostálgico da situação atual do pensamento filosófico, pois em seu sentido original - isto é, como o empreendimento interdisciplinarmente arranjado de um diagnóstico da realidade social - essa tradição já não existe há muito tempo. Quando, todavia, empreendo a seguir uma tal tentativa, com isso entáo náo pode estar associada a intenção de explorar as condiçóes para uma revitalização da antiga tradição frankfurtiana: nem acredito que o programa de pesquisa original sequer mereça ainda um desenvolvimento que tenha sido interrompido, e nem estou convencido de que a realidade social complexificada e rapidamente mutável se deixe pesquisar sem mais no quadro de uma única teoria - que seja ela interdisciplinarmente arranjada. "Teoria Crítica da sociedade", então, não deve ser entendida a seguir no sentido do programa original da Escola de Frankfurt. Entretanto, com isso se deve entender mais do que uma referência a qualquer forma de teoria social que submeta simplesmente seu objeto a uma investigação ou diagnóstico críticos, já que isso vale de modo quase autoevidente para toda forma de teoria sociológica da sociedade que verdadeiramente mereça esse nome - para Weber não menos do que para Marx, para Durkheim não menos do que para Tönnies. Com "Teoria Crítica da sociedade" aqui se quer entender antes o tipo de pensamento socioteórico que compartilha com o programa original da Escola de Frankfurt, talvez mesmo com a tradição do hegelianismo de esquerda como um todo, uma forma determinada de crítica normativa: uma tal, a saber, que também esteja apta a prover informaçáo sobre a instância pré-científica em que seu próprio aspecto crítico esteja ancorado fora da teoria como interesse empírico ou experiência moral. No primeiro passo, quero apenas brevemente lembrar dessa herança hegeliana de esquerda da Teoria Crítica, pois considero que ela seja o único elemento teórico que ainda possa agir como uma premissa incontornável da antiga tradição no sentido de uma marca de identidade. Por meio de sua forma específica de crítica, a teoria social de tradição frankfurtiana se diferencia de todas as outras correntes ou direçóes da critica social. Somente depois dessa lembrança metodológica posso começar, então, a delinear a situação em que a Teoria Crítica da sociedade se encontra hoje. Quero empreender isso de modo que - em cuidadosa delimitação frente à teoria comunicativa de Habermas - esboce passo a passo as premissas fundamentais de uma perspectiva que possa satisfazer as exigências metodológicas da velha teoria. $\mathrm{O}$ núcleo dessa perspectiva consiste em um desdobramento do problema social anunciado no título de meu texto: a "dinâmica social do desrespeito". 


\section{Crítica e prática pré-científica}

O ponto de partida metodológico da teoria que Horkheimer procurou encaminhar no começo dos anos 1930 é determinado por um problema que se deve à tomada de uma peça de herança hegeliana de esquerda. Entre os discípulos de esquerda de Hegel, isto é, de Karl Marx a Georg Lukács, valia como autoevidência que a teoria da sociedade somente poderia realizar uma crítica a seu objeto na medida em que nele pudesse redescobrir um elemento de seu próprio aspecto crítico como realidade social; daí que fosse sempre necessário para esses teóricos um diagnóstico da sociedade que estivesse na situação de revelar um momento de transcendência intramundana. Horkheimer tinha a tarefa assim delineada diante dos olhos quando, em um de seus conhecidos artigos iniciais, define a particularidade da Teoria Crítica, ao designá-la como "a dimensão intelectual do processo de emancipação histórica” (Horkheimer, 1988(1937): p. 189)4; de fato, para ser capaz de tal realização, a teoria deve poder pensar conjuntamente sempre sobre sua emergência em uma experiência pré-científica e também em sua aplicação em uma práxis futura. Diferente de Lukács, porém, Horkheimer tem clareza de que, com uma tal determinação de partida, não apenas estabelece uma exigência metodológica, mas também invoca o trabalho regrado e conjunto com a pesquisa individual das ciências sociais, uma vez que a Teoria Crítica somente pode afirmar sua própria dependência de uma dimensão pré-científica da emancipação social na medida em que, sob a forma de uma análise sociológica, ela dê conta de como se encontram constituídas a situação da consciência ou a prontidão para a emancipação da população. A relação específica à qual Horkheimer, em continuação do hegelianismo de esquerda, trouxe uma para a outra teoria e prática pressupóe uma determinação dos impulsos sociais que, no processo histórico, pressionam a partir de si para a crítica e superação das formas estabelecidas de dominação; daí que a Teoria Crítica é, em seu núcleo mais interno - e sejam quaisquer outras suas coincidências com outras formas de crítica social - informada pela determinação virtualmente sociológica de um interesse emancipatório na própria realidade social ${ }^{5}$.

4 Sobre o conceito de crítica em Horkheimer, cf. Küsters, 1980. A coletânea de S. Benhabib, W. Bonß eJ. McCole (1993) inclui contribuições interessantes.

5 Cf. DUBIEL, (1978, Parte A). 
Ora, uma série de explorações teórico-históricas puderam desde então mostrar que os meios de explicação sociofilosóficos do Instituto de Frankfurt não foram suficientes para implementar esse ambicioso objetivo na prática de pesquisa: Horkheimer, no começo, permanece preso a uma filosofia da história marxista que pode admitir um interesse pré-científico somente na classe proletária (BENHABIB, 1986, p. 147 e ss); Adorno faz da crítica marxista do fetichismo já bem cedo um ponto de partida tão decisivo para sua crítica da sociedade que ele náo pôde mais detectar na cultura social cotidiana qualquer resquício de uma transcendência intramundana (HABERMAS, 1981) mente dos pesquisadores marginalizados do Instituto, de Walter Benjamin ou ainda de Otto Kirchheimer, poderiam talvez ter vindo os impulsos teóricos para procurar uma outra entrada mais produtiva para os potenciais emancipatórios da realidade social ${ }^{7}$. Assim, Horkheimer e seu círculo permaneceram, de modo geral, presos a um funcionalismo marxista que os induziu a supor dentro da realidade societária um círculo tão fechado de dominação capitalista e manipulação cultural que ali dentro não poderia permanecer qualquer espaço mais para uma zona de crítica prático-moral. O problema assim condicionado, a saber: o constrangimento de por um lado estar informada teoricamente por uma instância pré-científica de emancipação cuja existência, por outro lado, não poderia mais ser empiricamente designada este problema, então, ainda deveria se agudizar para a tradição fundada por Horkheimer na medida em que as esperanças de mudança antes praticamente alimentadas devessem perder em plausibilidade e poder de convencimento: com a vitória do fascismo e a implementação final do stalinismo derreteu toda possibilidade de dar à perspectiva crítica da teoria um apoio objetivo em uma instância pré-científica, seja ela um movimento social ou em um interesse objetivo. A passagem da Teoria Crítica ao negativismo histórico-filosófico de Adorno marca finalmente o ponto histórico no qual o empreendimento de uma confirmação sócio-histórica da crítica chega à paralisação; nas reflexôes da Dialética do Esclarecimento, permanece como único lugar no qual algo como uma transcendência intramundana ainda pode se consumar apenas a experiência da arte moderna (HORKHEIMER; ADORNO, 1969).

Ver vol. I, cap. IV, p. 2.

Cf. sumarização: HONNETH, A. Kritische Theorie. Vom Zentrum zur Peripherie einer Denktradition, em HONNETH 1999. p. 25 e ss. 
De volta do exílio à Alemanha Ocidental, Horkheimer e Adorno não intentaram mais nenhuma mudança essencial nas premissas empíricas de seu empreendimento crítico. De fato, deixa-se questionar se ambos pensadores mantiveram efetivamente a abordagem da Dialética do Esclarecimento sem correçôes até o final de suas vidas; inquestionável, porém, é a circunstância de que ambos não queriam acreditar em uma possibilidade intramundana da emancipação: de parte de Adorno a Dialética negativa mostra isso, de parte de Horkheimer sua tardia orientação ao pessimismo filosófico de Schopenhauer indica isso (ADORNO, 1966; HORKHEIMER, 1971) ${ }^{8}$. Como quer que sejam individualmente, com as orientaçôes fundamentais de seus escritos tardios, Horkheimer e Adorno deixaram para trás um problema que, desde então, tem de estar no início de cada tentativa de uma reconexão com a Teoria Crítica, a saber: enquanto o modelo hegeliano de esquerda tiver de ser efetivamente preservado, deve ser efetivamente criada novamente uma entrada teórica para aquela esfera social na qual um interesse pela emancipação possa ser ancorado pré-cientificamente. Sem a demonstração efetiva, de qualquer modo, de que ao encontro da perspectiva crítica dentro da realidade social vem uma necessidade ou um movimento, hoje a Teoria Crítica não se deixa continuar de modo algum, uma vez que ela não se diferencia mais de outras abordagens da crítica social graças a uma superioridade no conteúdo de explicação sociológica ou em procedimentos de fundamentaçáo filosófica, mas apenas e tão somente graças à tentativa não abandonada de dar aos padróes da crítica um apoio objetivo na prática pré-científica. Como, porém, no decurso da história da Teoria Crítica essa esfera foi soterrada, hoje ela deve ser trazida novamente à luz em um pesado trabalho conceitual: na tarefa de desenvolver categorialmente a realidade social de tal modo que nela se torne novamente visível um momento de transcendência intramundana vejo, pois, o problema chave da atualização da teoria social crítica. Nessa medida, a pergunta sobre fundamentalmente como se deve reagir a esse problema pode servir como guia teórico por meio do qual a tentativa de uma situação da Teoria Crítica pode inicialmente se orientar.

8 Para a Teoria Crítica do pós-guerra, ver, em geral, Wiggershaus, 1986, cap. 6. 


\section{Caminhos alternativos de renovação da tradição}

Revisando a problemática esboçada até aqui, deixam-se distinguir sem muito esforço duas posturas de resposta opostas. Na primeira dessas duas correntes, a crítica social negativista que Adorno praticou em seus escritos tardios é radicalizada uma vez mais, de modo que uma autodissoluçáo do núcleo social da sociedade é diagnosticada como um todo; os fenômenos que assim adentram o palco são o crescimento completamente descontrolado de grandes sistemas técnicos, a autonomização dos imperativos sistêmicos frente ao mundo da vida social e, finalmente, o esvaziamento rapidamente levado a cabo da personalidade humana. Se, de fato, a enumeração de tais tendências de desenvolvimento evoca também lembranças do tipo de diagnóstico que já foi desenvolvido por autores conservadores como Arnold Gehlen, hoje, pelo contrário, ela se encontra principalmente em círculos teóricos que buscam se ocupar da herança negativista de Adorno no espaço de língua alemá, em primeiro lugar se prestam a isso os escritos de Stefan Breuer, enquanto no quadro internacional não raramente são os membros do pós-estruturalismo francês aqueles que movem tais fenômenos sociais para ponto central de seus diagnósticos sociais ${ }^{9}$. A figura teórica que é retirada do mundo da vida social nessas diferentes variaçóes de uma crítica social negativista é sempre marcada da mesma forma por uma tendência à desumanização: em Breuer, é a de uma crítica quase religiosa na onipotência da técnica e da ciência; no Foucault da fase média, é o reagir passivo à estratégia dos aparatos de poder; em Baudrillard, por fim, é a propensáo massivamente expandida à mera simulação, que deixa tornar os humanos hoje de modo geral meros objetos de um poder sistêmico que se reproduz de modo autopoiético. Fosse, porém, a realidade social assim pensada, então é óbvio quais consequências teóricas são associadas com isso a nosso problema: aquela forma de crítica, que procura localizar a si mesma dentro da própria realidade societária deve logo parecer inválida, uma vez que esta não é mais constituída de tal modo que, em seus desvios sociais, interesses ou disposiçôes emancipatórias se deixem absolutamente

9 Cf. exemplarmente: BREUER, S. Die Gesellschaft des Verschwindens. Von der Selbstzerstörung der technischen Zivilisation. Hamburg: Junius, 1992; FOUCAULT, M. Überwachen und Strafen. Frankfurt am Main: Suhrkamp, 1976. 
encontrar. Com a radicalização da crítica da reificação pelo Adorno tardio, de todo esforço por ainda designar um momento de transcendência intramundana a fim de prover à crítica um apoio social é finalmente retirada a base socioteórica: a tentativa de adentrar à prática pré-científica em uma relação reflexiva teria encontrado seu fim com essa forma de uma teoria crítica da sociedade.

Que este não necessariamente precisa ser o caso deixa claro a segunda corrente teórica na qual a tradição da Teoria Crítica encontra hoje continuação, pois a teoria habermasiana da comunicação - à qual naturalmente faço referência aqui - apresenta um movimento contrário à teoria social negativista exatamente no sentido de que ela justamente reabriu a passagem a uma esfera emancipatória da ação. A construção da teoria da ação comunicativa se deixa entender como redenção da tentativa de acessar novamente os mecanismos categoriais com ajuda dos quais a ideia de Horkheimer de uma crítica social deveria hoje ser mais uma vez revivida: a essa tentativa serve em primeiro lugar a conversão do paradigma marxista da produção no paradigma da ação comunicativa, em cuja estrutura deve ficar claro que as condiçóes do progresso social não estão investidas no trabalho social, mas na interação social; a partir daqui, o próximo passo leva ao desdobramento de uma pragmática da fala que deve esclarecer quais pressupostos normativos, especificamente, são os que constituem o potencial emancipatório da ação comunicativa; e finalmente, em um terceiro passo, é construído sobre isso o esboço de uma teoria da sociedade, que segue o processo de racionalização da ação comunicativa até o ponto histórico em que ele leva à formação de mecanismos de controle (HABERMAS, 1981). Habermas conhecidamente deixa sua teoria da sociedade desaguar em um diagnóstico de tempo, de acordo com o qual hoje o poder do sistema que se autocontrola cresceu tanto que eles se tornaram uma ameaça às realizaçóes comunicativas do mundo da vida: sob a força corrosiva com a qual os mecanismos de controle do dinheiro e do poder burocrático adentram a cultura cotidiana, o potencial humano para o entendimento comunicativo começa a se dissolver (HABERMAS, 1981) ${ }^{10}$. Nessa figura de uma colonização do mundo da vida, a teoria habermasiana da sociedade

10 Ver vol. II, cap. 8. 
parece, enfim, concordar com aquela crítica social pessimista que já havíamos encontrado naquelas correntes negativistas de um reavivamento da Teoria Crítica: ambas as abordagens se assentam sobre a concepção de um diagnóstico de tempo de que a autonomização de forças sistêmicas pode hoje levar a uma dissolução do núcleo social da sociedade. A grande e decisiva diferença, contudo, consiste em que Habermas é capaz de entregar um conceito sistemático daquilo que é correntemente ameaçado pela dominação dos sistemas: onde vigem nas abordagens teóricas negativistas as premissas não esclarecidas de uma mal articulada antropologia, encontra-se, em sua abordagem, uma teoria da linguagem que pode convincentemente mostrar que o potencial vulnerável dos humanos é sua capacidade para o entendimento comunicativo. Ao contrário de todas as outras variaçôes, a reformulação habermasiana da Teoria Crítica contém uma ideia, que pode expôr a estrutura daquela ação prática que ameaça ser destruída pelas tendências de desenvolvimento da sociedade criticadas.

A partir daqui, é fácil observar que, em sua construção formal, a teoria habermasiana da comunicação preenche as exigências que Horkheimer havia colocado a uma crítica social em seu programa inicial: assim como este último a tem no trabalho social, também aquele possui no entendimento comunicativo uma esfera pré-científica da emancipação à qual a crítica pode apelar a fim de designar seu aspecto normativo dentro da realidade social. A comparação com o modelo crítico de Horkheimer, porém, agora também torna visível na teoria habermasiana um problema que quero tomar como ponto de partida de minhas reflexóes subsequentes: ele toca na questão de como aquela conexão reflexiva que deve existir entre a prática pré-científica e a Teoria Crítica deve ser mais precisamente determinada. Quando Horkheimer formulou seu programa, ele ainda tinha diante dos olhos - perfeitamente no sentido da tradição marxista - um proletariado que já poderia ter adquirido um sentimento a respeito da injustiça do capitalismo no processo de produção: essa experiência moral, essa sensação da injustiça - essa era sua concepção - a teoria deveria articular sistematicamente apenas no nível reflexivo a fim de dar à sua crítica um apoio objetivo. Ora, hoje sabemos, e o próprio Horkheimer teria podido saber com um olhar mais sóbrio, que classes sociais não vivenciam experiências como um único 
sujeito e absolutamente não possuem um interesse comum e objetivo; aliás, por bons motivos, perdemos a concepção de que se deixe atribuir interesses ou experiências emancipatórias a um grupo de pessoas que compartilham apenas a situação socioeconômica umas com as outras. Mas, hoje, na construção da teoria, o que pode entrar no lugar que, em Horkheimer, aquelas experiências morais haviam assumido e com as quais ele - aqui completamente um discípulo de Georg Lukács - via a classe trabalhadora como um todo equipada? A Teoria Crítica deve confiar, como vimos em retrospecto, poder designar as experiências e perspectivas empíricas que já de modo pré-científico provêm um indicador para que seu aspecto normativo não fique sem aquele apoio na realidade. Quais experiências de tipo sistemático, ou ainda: quais fenômenos, quero ainda perguntar, assumem na teoria habermasiana o papel de prover testemunho cotidiano da coerência da crítica antes de qualquer reflexão científica? Minha suposição é que nesse lugar abre-se na teoria da ação comunicativa uma fissura cuja origem não é contingente, mas antes, que possui um caráter sistemático.

\section{Práxis pré-científica e experiência moral}

Com sua conversão da Teoria Crítica do paradigma da produção para o paradigma da comunicação, Habermas abriu os olhos a uma esfera social que preenche todos os requisitos para uma afirmação da transcendência intramundana; afinal, na ação comunicativa, os sujeitos se encontram em um horizonte de expectativas normativas cuja decepção sempre se torna fonte de exigências morais que apontam para além das respectivas formas de dominação estabelecidas. O que eram para Horkheimer as relaçóes de produção capitalistas, que impóem limites injustificáveis à capacidade humana para o trabalho, nesse sentido são, para Habermas, as relaçóes de comunicação societárias por meio das quais o potencial emancipatório do entendimento intersubjetivo é estreitado de modo não justificável. Mas especificamente quais justificativas normativas são essas que o processo de interaçáo contém, Habermas deduz com ajuda de sua concepção de uma pragmática universal: de acordo com ela, aquelas regras de fala que repousam na ação comunicativa possuem um caráter normativo na medida em que igualmente determinam os pressupostos de uma comunicação livre de 
dominação entre os humanos ${ }^{\prime \prime}$. Fossem essas condiçôes que estão investidas na linguagem observadas como o núcleo normativo que está estruturalmente investido na comunicação entre humanos, então a perspectiva crítica que está incrustada na teoria habermasiana da sociedade aparece de modo um tanto mais preciso: com ela deve-se tratar de analisar os estreitamentos sociais e cognitivos que contrapôem barreiras a uma aplicação desimpedida daquelas regras de linguagem. Com sua orientação pela pragmática universal, Habermas trilhou um caminho que leva a identificar o potencial normativo da interação social com as condiçóes linguísticas de um entendimento livre de dominação. Tâo grandes quanto possam ser as vantagens que acompanham uma tal forma teórico-linguística do paradigma da comunicação, tão agravantes são, avesso, as desvantagens que estão internamente associadas com ela. Uma primeira dificuldade já se mostra, de fato, quando nos perguntamos, no sentido de Horkheimer, quais experiências morais devem corresponder àquele aspecto crítica dentro da realidade social.

Para Habermas, a instância pré-científica que provê à sua perspectiva normativa um apoio social na realidade deve ser aquele processo societário que traz as regras linguísticas do entendimento a seu desdobramento: n' $A$ teoria da ação comunicativa, essa ocorrência é designada como racionalização comunicativa do mundo da vida. Agora, um tal processo é tipicamente algo que - deixa-se dizer com Marx - ocorre pelas costas dos sujeitos participantes: seu curso não é nem levado a cabo por intençóes individuais, nem é claramente dado à consciência de um único indivíduo. A ocorrência emancipatória na qual Habermas ancora criticamente a perspectiva normativa de sua Teoria Crítica absolutamente não se assenta nas experiências morais dos sujeitos participantes enquanto tal ${ }^{12}$, pois estes experimentam um dano àquilo que nós podemos observar como suas expectativas morais, como seu "moral point of view", não como estreitamento de normas de fala intuitivamente dominadas, mas como ferimento de demandas por identidade levantadas durante a socialização. Um processo de racionalização

II Comp. princip. Jürgen Habermas Diskursethik - Notizen zu einem Begrundungsprogramm", em Moralbewußtsein und kommunikatives Handeln, Frankfurt am Main, 1983, p. 53 e ss.

12 Isso também objetou, obviamente com outra ênfase, Georg Lohmann (1993, aqui p. 288). 
comunicativa do mundo da vida pode historicamente bem ter ocorrido ou ocorrer, mas nas experiências dos sujeitos humanos, em todo caso, ele náo se reflete como um fato moral. Daí que, para a instância pré-científica à qual a perspectiva normativa da teoria habermasiana alude reflexivamente, absolutamente não se deixa encontrar dentro da realidade social um correspondente: sua concepção não é investida da mesma maneira como a teoria de Horkheimer (todavia, esta sob influência de uma ilusão também destrutiva) com a ideia de ajudar na expressão de experiência existente de injustiça social.

Uma saída do dilema assim delineado aponta apenas a ideia de desdobrar o paradigma comunicativo desenvolvido por Habermas mais fortemente em direção a seus pressupostos teóricos intersubjetivos e até mesmo sociológicos; com isso, aqui é apenas mencionada provisoriamente a sugestáo de não identificar simplesmente o potencial normativo da interação social com as condiçóes linguísticas de um entendimento livre de dominação. Nessa direção já indicava a tese de que experiências morais não se inflamam pelo estreitamento de competências linguísticas, mas se formam através de ferimentos das demandas por identidade levantadas durante a socialização. Na mesma direção apontam hoje investigaçóes como aquela de Thomas McCarthy, que procura dar ao paradigma habermasiano da comunicação uma moldura mais próxima da experiência ao reconstruir os pressupostos normativos da interação com ajuda da etnometodologia (MCCARTHY, 1993). A fim de poder entender melhor quais expectativas morais estão incrustadas no processo cotidiano da comunicação societária, sugere-se como primeiro passo o engajamento com estudos históricos e sociológicos que são dedicados à resistência de classes socialmente subalternas: uma vez que, de fato, seus membros não são culturalmente especializados na articulação de experiências morais, expressa-se em suas enunciaçôes, em certa medida, antes de qualquer influência filosófico-acadêmica a que as expectativas normativas são direcionadas no cotidiano social. A discussão com tal tipo de investigação torna claro com grande regularidade que não é a orientação por princípios morais positivamente formulados, mas a experiência do ferimento de concepçóes de justiça intuitivamente dadas que motivacionalmente repousa no comportamento social de protesto das classes subalternas. E o núcleo normativo de tais con- 
cepçóes de justiça representam sempre expectativas que se conectam com o respeito à dignidade, honra ou integridade individuais (conf. exempl. Moore, 1982) ${ }^{13}$. Fossem esses resultados generalizados agora para além de seus respectivos contextos de investigação, sugere-se a então consequência de ver na aquisição de reconhecimento social a pressuposição normativa da ação comunicativa: sujeitos se relacionam no horizonte da expectativa recíproca, a fim de encontrar reconhecimento como pessoas morais e para suas realizaçóes sociais. Se a tese assim aludida for plausível, então emerge como uma consequência adicional também a referência aos eventos que são percebidos no cotidiano social como injustiça moral: tais casos estáo presentes para os concernidos sempre que, ao contrário de sua expectativa, um reconhecimento visto como merecido não ocorre. As experiências morais pelas quais sujeitos humanos passam tipicamente em tais situaçóes, eu gostaria de caracterizar como sentimentos de desrespeito social.

Com essas reflexóes, já topamos em um ponto no qual se delineiam os primeiros traços de uma alternativa frente à moldura teórico-linguística do paradigma da comunicação. Seu ponto de partida representa a consideração de que os pressupostos normativos da interaçáo social náo se deixam apreender em toda a sua amplitude quando são determinados somente pelas condições linguísticas de um entendimento livre de comunicação: antes, deve-se atentar acima de tudo para o fato de que é a imputação de reconhecimento que liga os sujeitos a expectativas normativas através da entrada em relaçóes comunicativas. Fosse o paradigma da comunicação expandido dessa maneira para além do quadro teórico-linguístico, vem à vista, no mais, em que medida cada lesão dos pressupostos normativos da interação deve se assentar diretamente nos sentimentos morais dos participantes: uma vez que a experiência do reconhecimento representa uma condiçáo na qual se pendura o desenvolvimento da identidade humana como um todo, à sua denegação, isto é, ao desrespeito, acompanha necessariamente a sensação de uma ameaçadora perda da personalidade. Diferentemente de Habermas, existe aqui uma forte conexão entre os ferimentos que são infligidos à imputação normativa da interação social e

13 A ele também me referi em Moralbewußtsein und soziale Klassenherrschaft, em Die zerissene Welt des Sozialen, de Axel Honneth (1990, p. I82 e ss). 
as experiências morais pelas quais os sujeitos passam em suas comunicaçóes cotidianas: fossem feridas aquelas condiçôes, quando a uma pessoa é negado o merecido reconhecimento, a isso então a concernida reage, em geral, com sentimentos morais que acompanham a experiência do desrespeito, isto é, vergonha, raiva e indignação. Dessa forma, finalmente, um paradigma comunicativo que é formado não teórico-linguisticamente, mas com relação a uma teoria do reconhecimento também pode fechar o espaço que Habermas deixara em aberto em seu desenvolvimento do programa horkheimeriano, pois aquelas sensaçóes de injustiça que acompanham formas estruturais do desrespeito representam um fato pré-científico ao qual uma crítica das relaçóes de reconhecimento pode socialmente referir sua própria perspectiva teórica.

Agora, a consideração que acabo de sumarizar contém tantos pressupostos náo esclarecidos, que neste lugar não posso fundamentá-los por completo. A parte de minha interpretação que se relaciona às pressuposiçôes comunicativas de um desenvolvimento bem-sucedido da identidade do ser humano, tentei justificar em um livro que reconstrói o modelo de reconhecimento do jovem Hegel com auxílio de George H. Mead; ali se encontra também uma distinção de três padróes de reconhecimento recíproco que considero necessários e que aqui, porém, risquei apenas de passagem (HONNETH, 1992) 14. Uma outra parte de minhas consideraçôes, a saber, aquela em que afirmo que a expectativa de reconhecimento social pertence à estrutura da ação comunicativa, eu mesmo não estou em condiçốes de justificar em todas as suas consequências nesse momento, pois isso exigiria uma solução da difícil tarefa de deixar adentrar no lugar da pragmática universal habermasiana uma concepção antropológica que pode explicar as pressuposiçóes normativas da interação social como um todo. Em vista da questão, em que situação se encontra hoje a Teoria Crítica, contudo, outros aspectos possuem maior significado. Se as relaçôes de comunicação social devem ser primariamente analisadas com relação a quais formas estruturais de desrespeito elas produzem, então também a perspectiva crítica do diagnóstico deve mudar perante a abordagem habermasiana: no ponto central não devem mais ficar as tensóes entre sistema e

14 Ver cap. 5 
mundo da vida, mas as causas sociais que são responsáveis pelo ferimento sistemático de condiçóes de reconhecimento. A atenção da análise diagnóstica deve se realocar da autonomização dos sistemas para a distorção e lesão das relaçóes de reconhecimento social. Frente a Habermas, como veremos, isso levará também a uma reavaliação do papel que a experiência do trabalho tem de desempenhar no quadro categorial de uma Teoria Crítica.

\section{Patologias da sociedade capitalista}

Na tradição da Escola de Frankfurt, constitui-se a tendência de tomar como a "desordem" decisiva das sociedades modernas o fato de que a razão instrumental encontrou predominância frente a outras formas do agir e do saber: todas as ocorrências ou fenômenos que podem ocorrer "patologicamente" na realidade social são interpretados como consequência de uma autonomização de disposições sociais que são associadas ao objetivo da dominação da natureza. Também em Habermas prossegue ainda essa mesma tendência na medida em que ele deixa o esboço de sua Teoria da ação comunicativa desembocar em um diagnóstico de tempo que assume o perigo de uma "colonizaçáo" do mundo da vida por sistemas organizados racionalmente com respeito a fins: repetidamente aparece como a "desordem" pela qual o contexto de vida de nossa sociedade seria ameaçado a tendência a uma crescente supremacia de orientaçóes instrumentais, mesmo quando sua emergência não é mais explicada simplesmente pela finalidade da dominação da natureza, mas através do aumento da racionalidade organizativa. Quase não é necessária, finalmente, a menção adicional de que naturalmente as teorias sociais negativistas na sucessão de Adorno também estão determinadas por uma figura diagnóstica na qual é um tipo preciso de razão instrumental que cresce para se tornar uma força ameaçadora da vida na técnica, ciência e sistemas de controle. $\mathrm{O}$ que deve ser visto como característico para todas essas abordagens de um diagnóstico é o fato de que patologias ou anomalias sociais são sempre medidas pelo estado que o desenvolvimento da racionalidade humana marca: como desvios de um ideal que deve ser categorialmente pressuposto como uma forma de sociedade "saudável" ou intacta, podem valer aqui tão somente unilateralizaçóes que se consumam nas orientaçóes cognitivas dos humanos. A uma tal perspectiva, também ela uma herança do hegelianismo de esquerda, 
acompanha correspondentemente um afunilamento, relacionado à teoria da racionalidade, do diagnóstico crítico, pois todas aquelas patologias sociais que não dizem respeito ao nível de desenvolvimento da racionalidade humana absolutamente não podem aparecer à vista. Para aquelas desordens da vida societária, digamos, que Durkheim tinha diante dos olhos quando investigou o processo de individualização, deve faltar na tradição da Escola de Frankfurt aquela sensibilidade diagnóstica, já que elas se consumam, a saber, como dissolução de uma força social de ligaçáo que está em ligação apenas indireta com mudanças da racionalidade humana ${ }^{15}$.

$\mathrm{Na}$ suposição fundamental que desenvolvi até agora em minha tentativa de situação, não pode ter sentido dar-se por satisfeito com um olhar de tal modo afunilado sobre as desordens e patologias de nossa sociedade: como se tornariam visíveis falsos desenvolvimentos da vida social que se conectam com as condiçóes estruturais do reconhecimento recíproco se só estão à disposição critérios para medir desvios que se relacionam ao estado da racionalidade humana? Tẫo logo o paradigma da comunicação não seja mais formulado apenas no sentido de uma concepção do entendimento racional, mas no sentido de uma concepção das condiçóes do reconhecimento, também o diagnóstico crítico não precisa mais ser pressionado no esquema afunilado de uma teoria da racionalidade, já que, como um critério para aquilo que deve valer como "desordem" ou falso desenvolvimento da vida social, não podem mais ser utilizadas as condiçôes racionais do entendimento livre de dominação, mas devem ser utilizados os pressupostos intersubjetivos do desenvolvimento da identidade humana. Tais pressupostos se encontram nas formas de comunicação social nas quais o indivíduo cresce, encontra uma identidade social e, finalmente, aprende a conceber-se, ao mesmo tempo, como um membro dotado dos mesmos diretos que outros e particular de uma sociedade. Ora, sejam essas formas de comunicação de tal modo constituídas que elas não oferecem a medida de reconhecimento que é necessária para a administração daquelas diferentes tarefas identitárias, então isso deve aparecer como indicador de falso desenvolvimento de uma sociedade. Assim, são patologias do reconhecimento

15 Para o problema de uma determinação de patologias sociais comp. "Pathologien des Sozialen. Tradition und Aktualität der Sozialphilosophie" (HONNETH, 2000). 
que vêm ao centro do diagnóstico, tão logo o paradigma da comunicação seja conceitualizado não mais de modo teórico-linguístico, mas com relação à teoria do reconhecimento: os conceitos fundamentais de uma análise da sociedade, de modo correspondente, devem ser construídos de tal forma que eles permitam apreender distorçôes ou déficits em estruturas sociais de reconhecimento, ao passo que o processo de racionalização societária perde sua posição central.

Entretanto, essas considerações deixam completamente indeterminado em qual relação, afinal, aquelas patologias do reconhecimento estão com a estrutura social de uma dada sociedade. Se o modelo até aqui delineado de uma Teoria Crítica deve estar na situação de mais do que uma mera análise normativa do presente, ele deve poder mostrar, acima de tudo, as causas socioestruturais que são respectivamente responsáveis pela distorção nas estruturas sociais de reconhecimento. Somente então, a saber, seria decidível se de fato existe uma conexão sistemática entre determinadas experiências de desrespeito e o desenvolvimento estrutural da sociedade. Aqui devo me limitar a poucos comentários, os quais, acima de tudo, devem servir à função de preparar um passo adicional de distanciamento da forma habermasiana do paradigma da comunicação. Com recurso ao jovem Hegel, como já mencionado, distingui três formas de reconhecimento social que podem valer como pressupostos comunicativos de uma formação bem-sucedida da identidade: a devoção emocional em relaçóes íntimas, como o amor e a amizade, o reconhecimento jurídico como membro moralmente imputável de uma sociedade e, finalmente, a estima social às contribuiçôes e habilidades individuais. A pergunta - como se constitui a estrutura de reconhecimento de uma determinada sociedade - somente pode ser respondida, pois, através de investigaçóes que se ocupem com o estado empírico no qual se encontram respectivamente as encarnaçóes institucionais desses três padrôes de reconhecimento. Para nossa sociedade, pois, isso demandaria estudos sobre práticas de socialização, formas de família e relaçóes de amizade, por um lado, em segundo lugar, sobre o conteúdo e cultura de aplicação prática do direito positivo e, finalmente, sobre os padrốes fáticos da estima social. A respeito dessa última dimensão do reconhecimento, deixa-se agora não apenas supor, mas, sob a consideração de investigaçóes comparativas, com um tanto quanto de certeza, também 
afirmar que a estima social de uma pessoa se mede extensivamente por quais contribuiçôes ela executa para a sociedade na forma de um trabalho formalmente organizado. As relaçóes de reconhecimento são, no que diz respeito à estima social, em grande medida enredadas com a distribuição e organização do trabalho societário. Isso, porém, exige dar no programa aqui desenvolvido de uma Teoria Crítica um maior significado à categoria do trabalho do que teoria da ação comunicativa lhe deixa receber.

\section{Trabalho e reconhecimento}

Já um breve olhar nas investigaçôes que tratam das consequências psíquicas do desemprego traz inequivocamente para diante dos olhos que à experiência do trabalho deve ser atribuída uma posição central na concepção aqui emergente, pois à oportunidade de perseguir um trabalho economicamente remunerado e, deste modo, socialmente regulado, hoje está associada também a aquisição daquela forma de reconhecimento que nomeei estima social. Mas, por outro lado, essa revalorização da experiência do trabalho não deve conduzir a recuar para baixo do nível que Habermas estabeleceu já há vinte anos com seu expurgo categorial do conceito de trabalho, pois, na tradição marxista e também no próprio Horkheimer, o trabalho societário é tão elevado a um fator formativo que apenas um conceito de trabalho o mais sóbrio possível, purificado de implicaçóes normativas, pode proteger do perigo da formação de uma tal ilusão. Dessa tendência oposta, leva-se à questão de até qual limite o conceito de trabalho pode ser neutralizado sem, com isso, ao mesmo tempo, perder o significado de uma fonte central de experiências morais: por um lado, o processo de trabalho societário não pode mais ser, enquanto tal, estilizado em um processo de formação da consciência emancipatória, ainda como na tradição do marxismo ocidental; por outro lado, porém, ele deve permanecer categorialmente incrustado de referências morais a experiências, na medida em que seu papel para a obtenção de reconhecimento social não deva sumir de vista ${ }^{16}$.

16 Comp. com minhas reflexões em "Arbeit und instrumentales Handeln", em Axel Honneth und Urs Jaeggi (1980). As réplicas de Habermas (1984, p. 475 e ss., nota 14) me parecem, de fato, válidas, no que concerne às questões da organização do trabalho; porém, não me parece realmente elucidativa sua resposta com relação ao problema de como deva ser constituído o conteúdo descritivo de um conceito de trabalho que ainda deva cumprir a tarefa de uma apreensão crítica das relações de trabalho existentes. 
De fato, na nova teoria da sociedade de Habermas, aquele conceito da "ação instrumental" ao qual ele havia transferido o conceito marxista de trabalho, não desempenha mais qualquer papel sistemático: as distinçóes centrais que ele hoje toma na prática dos humanos não se medem mais pelas diferenças entre os respectivos contrapartes - natureza ou parceiro - mas pelas diferenças na coordenação de ações pensadas por princípio como teleológicas. Mas essa estratégia conceitual leva a que a experiência do trabalho absolutamente não apareça sistematicamente mais no quadro categorial da teoria; tão pouco quanto quais experiências são vivenciadas em contato com a natureza exterior desempenha um papel para a ideia habermasiana da formação da identidade pessoal, pouco desempenha um papel para sua teoria da sociedade o modo como o trabalho societário é respectivamente dividido, organizado e estimado. Quando, porém, a formação da identidade individual também depende da estima social de que o próprio trabalho desfruta dentro da sociedade, então o conceito de trabalho não deve ser arranjado de tal modo que ele desvie categorialmente essas conexóes psíquicas; a consequência constrangedora, de fato, seria a de que para a teoria da sociedade permaneceriam ininteligíveis, ou mesmo invisíveis, todos aqueles esforços que anseiam por uma reavaliação ou reformulação de determinados traços do trabalho. Determinadas zonas da crítica pré-científica vêm à vista apenas na medida em que elas são analisadas à luz de um conceito de trabalho que inclui categorialmente a dependência individual quanto ao reconhecimento social da própria atividade.

Para a análise adicional da conexão em que trabalho e reconhecimento se encontram um com o outro, hoje é significativo acima de tudo o debate sobre o problema do trabalho doméstico não pago, que é conduzido em conexão com o feminismo ${ }^{17}$. No correr dessa discussão, de fato, tornou-se claro a partir de dois lados que a organização do trabalho societário é associada de modo mais próximo às normas éticas que regem respectivamente o sistema da estima social: sob o aspecto histórico, o fato de que a educação das crianças e o trabalho doméstico não foram

17 Comp. exemplarmente os trabalhos de Friedrich Kambartel, Angelika Krebs e Ingrid Kurz-Scherf no dossiê "Zur Sozialphilosophie der Arbeit", em Deutsche Zeitschrift für Philosophie, H. 2/1993, p. 237 e ss. Inovador para uma análise da relação entre trabalho e reconhecimento me parece, além disso, Gorz (1989, entre outras, partes II e III). 
valorizados como tipos de trabalho societário plenos de valor e necessários à reprodução só pode ser explicado com referência a pouca estima que lhes foi atribuída no quadro de uma cultura determinada por valores masculinos; sob o aspecto psicológico, emerge da mesma circunstância que, na divisão tradicional de tarefas, mulheres possam contar apenas com menores chances de encontrar dentro da sociedade a medida de reconhecimento social que forma a pressuposição necessária para um autoentendimento positivo. De ambas as linhas de pensamento, deixa-se derivar a consequência de que a organização e valorização do trabalho social desempenham um papel central para a estrutura de reconhecimento de uma sociedade: já que com a definição cultural da hierarquia de tarefas sociais define-se, de fato, qual medida de estima social o indivíduo pode receber por sua atividade e pelas propriedades a ela ligadas, as chances da formação individual da identidade se conectam diretamente através da experiência do reconhecimento com a instituição e a distribuição societárias do trabalho. Nessa zona pré-científica de reconhecimento e desrespeito, obviamente, apenas um conceito de trabalho que ainda seja normativamente arranjado de modo suficientemente sofisticado para poder incluir a dependência da confirmação social das próprias realizações e propriedades pode nos abrir os olhos.

\section{Conclusão}

Todas as reflexóes que apresentei até agora concorrem para a tese de que, nos variados esforços de uma luta por reconhecimento, é que a Teoria Crítica poderá justificar suas demandas normativas: as experiências morais pelas quais os sujeitos passam no desrespeito a suas demandas por identidade formam, em certa medida, a instância pré-científica com relação à qual se deixa mostrar que uma crítica das relações comunicativas não é completamente desprovida de apoio na realidade social.

Com essa tese emerge, agora, porém, levemente a impressão de que as sensaçóes de desrespeito, enquanto tal, seriam moralmente algo bom, a que em sua autojustificação a teoria pode se relacionar diretamente e sem restriçóes. O quão falsa é tal imputação, o quão altamente ambivalentes, por sua vez, são as experiências de injustiça, deixa claro uma citação: 
A maior parte dos jovens que se dirigia a nós estava frustrada. Eles não tinham qualquer perspectiva de futuro. Eu os apoiava e eventualmente os elogiava, a fim de elevar seu sentimento de autoestima. Tal reconhecimento fazia deles completamente dependentes da comunidade, à qual nós chamávamos de "camaradaria". Essa "camaradaria" virou, para muitos, uma espécie de droga, da qual eles não podem mais largar. Uma vez que eles não experimentam qualquer reconhecimento fora da "camaradaria”, eles são amplamente isolados e lhes faltam outros contatos sociais. (HASSELBACH; BONEGEL, 1993. p. 121).18

Essas frases são de um livro que o berlinense oriental Ingo Hasselbach escreveu sobre as experiências pelas quais ele passou, antes de sua saída, nos grupos da cena jovem neonazista. Embora a descrição dessas impressóes seja também marcada pela linguagem do jornalista que ajudou na preparação do manuscrito, ainda assim elas deixam claro com grande vividez para onde a experiência do desrespeito social pode levar politicamente: estima social pode ser buscada tanto em pequenos grupos militares cujo código de honra é dominado pela prática da violência quanto nas arenas públicas de uma sociedade democrática. A sensação de, de algum modo, ter caído fora da rede de reconhecimento social representa, em si, uma fonte motivacional altamente ambivalente para a revolta social e a oposição: a ela falta aquele índice de direcionamento normativo que estabeleceria por quais caminhos deve ser lutado contra a experiência do desrespeito e da humilhação. Uma teoria crítica da sociedade que quer desenvolver o paradigma habermasiano da comunicação no sentido de uma doutrina do reconhecimento não se encontra, pois, tão bem quanto possa ter soado até agora. De fato, ela pode encontrar na massiva sensação de desrespeito social aquele momento de transcendência intramundana que confirma pré-cientificamente que suas observaçôes diagnósticas são compartilhadas pelos concernidos: também estes vivenciam a realidade social do mesmo modo que a teoria a descreve, a saber, como uma realidade societária que não está suficientemente na situação de gerar experiências de reconhecimento. Mas, nessa confirmação pré-científica, a teoria não deve antever uma evidência de que também a direção normativa de sua crítica é compartilhada pelos concernidos. Assim, ela não pode mais - como ainda queria Horkheimer - conceituar a si mesma como a mera expressáo intelectual de um processo de

18 Conferir Die Abrechnung. Ein Neonazi sagt aus (HASSELBACH; BONEGEL, 1993. p. 121 e ss). 
emancipação já em movimento. Antes, essa teoria da sociedade deveria concentrar seus esforços na resolução de uma questão que Horkheimer, inteiramente sob o feitiço de uma grande ilusão, absolutamente ainda não poderia ter visto enquanto tal: como, de fato, teria de ser concebida uma cultura moral, que dá aos concernidos - aos desrespeitados e excluídos - a força individual para articularem suas experiências na esfera pública democrática ao invés de vivê-las nas contraculturas da violência.

\section{Referências}

ADORNO, T. W. Negative Dialektik. Frankfurt am Main: Suhrkamp Verlag, 1966.

BENHABIB, S. Critique, norm and utopia. A study of the foundations of Critical Theory. New York: Columbia University Press, 1986.

BENHABIB, S; BONß, W.; MCCOLE, J. On Max Horkheimer: new perspectives. Cambridge: The MIT Press, 1993.

BREUER, S. Die Gesellschaft des Verschwindens. Von der Selbstzerstörung der technischen Zivilisation. Hamburg: Junius, 1992.

DUBIEL, H. Wissenschaftsorganisation ud politische Erfahrung. Frankfurt am Main: Suhrkamp 1978.

FOUCAULT, M. Überwachen und Strafen. Frankfurt am Main: Suhrkamp, 1976.

GORZ, A. Kritik der ökonomischen Vernunft. Berlim: Rotbuch-Verlag 1989.

HABERMAS, J. Theorie des kommunikativen Handels. 2 vol. Frankfurt am Main: Suhrkamp, 1981.

HABERMAS, J. Moralbewußtsein und kommunikatives Handeln. Frankfurt am Main: Suhrkamp, 1983.

HABERMAS, J. Vorstudien und Ergänzungen zur Theorie des kommunikativen Handelns. Frankfurt am Main: Suhrkamp, 1984.

HASSELBACH, I.; BONEGEL, W. Die Abrechnung. Ein Neonazi sagt aus. Berlim; Weimar: Aufbau Verlag, 1993.

HONNETH, A. Kampf um Anerkennung. Zur moralischen Grammatik sozialer Konflikte. Frankfurt am Main: Suhrkamp, 1992.

HONNETH, A. Die zerrissene Welt des Sozialen. Frankfurt am Main: Suhrkamp, 1999.

HONNETH, A. Das Andere der Gerechtigkeit. Aufsätze zur praktischen Philosophie. Frankfurt am Main: Suhrkamp Verlag, 2000. 
HONNETH, A.; JAEGGI, U. Arbeit, Handlung, Normativität. Frankfurt am Main: Suhrkamp Verlag, 1980.

HORKHEIMER, M. Traditionelle und kritische Theorie. In: HORKHEIMER, M. Gesammelte Schriften, Band 4. Frankfurt am Main: Fischer Taschenbuch Verlag, 1988.

HORKHEIMER, M. Pessimismus heute. In: HORKHEIMER, M. Gesammelte Schriften, Band 7, Frankfurt am Main: Fischer Taschenbuch Verlag, 1985.

HORKHEIMER, M.; ADORNO, T. W. Dialektik der Aufklärung. Frankfurt am Main: Fischer Taschenbuch Verlag, 1969.

KÜSTER, G-W. Der Kritikbegriff der kritischen Theorie Max Horkheimers. Frankfurt am Main: VSVerlag für Sozialwissenschaften, 1980.

LOHMANN, G. Zur Rolle von Stimmungen in Zeitdiagnose. In: LOHMANN, G., FINKEITEL, H. Zur Philosophie der Gefühle. Frankfurt am Main: Suhrkamp, 1993.

MCCARTHY, T. Philosophie und kritische Theorie. Eine Reprise. In: MCCARTHY, T. Ideale und Illusionen. Dekonstruktion und Rekonstruktion in der kritischen Theorie. Frankfurt am Main: Suhrkamp, 1993.

MOORE, B. Ungerechtigkeit. Die sozialen Ursachen von Unterordnung und Widerstand. Frankfurt am Main: Suhrkamp, 1982.

WIGGERSHAUS, R. Die Frankfurter Schule. München; Wien: Carl Hanser Verlag, 1986. 